DOE/ER/75637--1

DE93 002419

\title{
GREENHOUSE EARTH: A TRAVELING EXHIBITION
}

\section{Final Report}

for Period September 1, 1991 - August 31, 1992

william H. Booth and Sanderson Caesar

The Franklin Institute Science Museum 20 th Street and The Benjamin Frankl in Parkway Phildelphia, PA 19103-1194

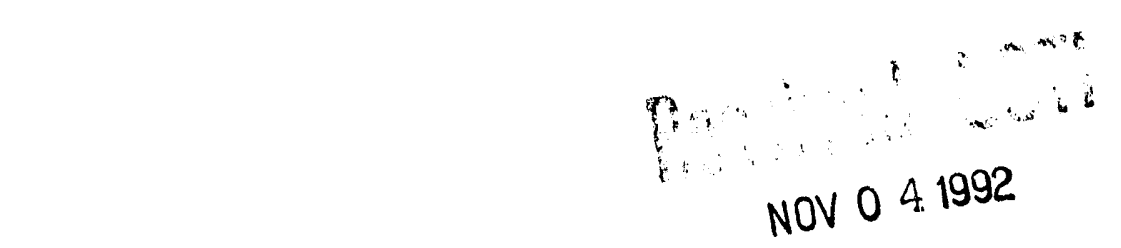

September 1992

Prepared for

THE U.S. DEPARTMENT OF ENERGY

AGREEMENT NO. DE-FG02-91ER75637 
This report was prepared as an account of work sponsored by the United states Government. Neither the United States nor the Department of Energy, nor any of their employees, nor any of their contractors, subcontractors, or their employees, makes any warranty, express or implied, or assumes any legal liability or responsibility for the accuracy, completeness, or usefulness or any information, apparatus, product or process disclosed or represents that its use would not infringe privately-owned rights. 


\section{ABSTRACT \\ Final Report \\ Greenhouse Earth: A Traveling Exhibition \\ Report NO. DOE/ER/75637 \\ submitted by \\ The Franklin Institute Science Museum \\ september 17,1992}

The Franklin Institute Science Museum hereby submits the final report on Greenhouse Earth: A Traveling Exhibition. This 3500 square-foot exhibit on global climate change was developed in collaboration with the Association of Science-Technology centers. The exhibit opened at The Franklin Institute on February 14, 1992, welcoming 291,000 visitors over its three-month stay. During its three-year tour, Greenhouse Earth will travel to ten U.S. cities, reaching two million visitors. Greenhouse Earth aims to deepen public understanding of the scientific issues of global warming and the conservation measures that can be taken to slow its effects. The exhibit features hands-on exhibitry, interactive computer programs and videos, a theater production, a "demonstration cart," guided tours, and lectures. supplemental educational programs at the Institute included a teachers preview, a symposium on climate change, and a "satellite field trip." The development of Greenhouse Earth included front-end and formative evaluation procedures. Evaluation includes interviews with visitors, prototypes, and summative surveys for participating museums. During its stay in Philadelphia, Greenhouse Earth was covered by the local and national press, with reviews in print and broadcast media. Greenhouse Earth is the first large-scale museum exhibit to address global climate change. 


\section{Final Report \\ Greenhouse Earth: A Traveling Exhibition \\ Report NO. DOE/ER/75637 \\ submitted by \\ The Franklin Institute science Museum \\ september 18, 1992}

The Franklin Institute science Museum hereby submits the final report on Greenhouse Earth: A Traveling Exhibition. This 5000 square-foot exhibit on global climate change was developed in collaboration with the Association of Science-Technology Centers. The exhibit opened at The Franklin Institute on February 14, 1992, welcoming 291,000 visitors over the course of its three-month stay in Philadelphia. During its three-year tour, Greenhouse Earth will travel to at least ten cities across the U.S. and will reach over two million visitors. (Exhibit tour schedule is attached).

\section{Project Description}

Greenhouse Earth is designed to focus public attention on global warming and to deepen understanding of the underlying scientific issues and the conservation measures that can be taken now to slow global warming. To address the public's broad range of learning styles, the exhibit and its accompanying educational programs were developed to meet the varying needs of school groups, sophisticated audiences, and family visitors. Greenhouse Earth features hands-on exhibitry, interactive computer programs and videos, an interactive science theater production, a "demonstration cart;" guided tours, and lectures for sophisticated audiences. Some key concepts and corresponding exhibitry include:

- Greenhouse effect: Feel The Heat

A large globe surrounded by a clear plexiglass sphere is lit by spotlights representing the sun. Visitors put their hands into holes in the plexiglass sphere to feel the heat trapped inside.

- See the Heat

As they walk into the exhibit area, visitors can see their image through an infrared camera. They can view hot objects or their breath and experiment with object that conduct heat and and others that do not.

- Atmospheric gases

Visitors breathe into a photospectrometer and compare the infrared absorption sjectrum of their breath with other gases. With this device, they learn that some gases absorb heat while others do not.

- weather

Visitors discover what makes weather through an interactive device showing convection currents in a fluid when heat is applied, and winds and movement of currents around continental land masses. 
- Weather vs. Climate

An interactive computer allows visitors to access an enormous database of reports from weather stations around the world. Visitors can chart the minimum and maximum temperatures on their birth dates over a period of many years to see trends and discover the difference between climate change and weather.

- Population

A "population slider graph" allows visitors to track population growth each year from 1800 to 2020; a video dramatically shows visitors how population is growing at an exponential rate; and a nearby computer lets visitors choose future scenarios of population growth, energy technologies of tomorrow. A supercomputer model predicts climate change at different dates in the future.

- Everyday conservation

A "kitchen" displays currently available energy-conserving appliances and building materials. visitors can feel differences in transmission of cold through different windows and turn a crank to light standard incandescent and compact fluorescent bulbs.

- What You Can Do

An interactive computer program asks visitors to audit their personal greenhouse gas emissions and then to go on a "diet" to cut emissions by $20 \%$. In the interactive process, visitors learn about conservation and new forms of energy.

\section{Educational programming}

During its three-month stay at The Franklin Institute, Greenhouse Earth also featured additional educational programs, including a Teachers Preview, a one-day symposium on climate change, and a "satellite field trip." These special programs are described below.

\section{- Teachers preview}

In the largest response The Franklin Institute has ever received for a teacher preview invitation, 1,500 teachers gathered on February 20, 1992 to tour Greenhouse Earth. Teachers from Philadelphia area school districts learned from museum educators about the ways that they could best make use of Greenhouse Earth during their class visits. Participants also received ure- and post-visit materials to further enhance students' learning about environmental concepts. (Teachers Guides are attached).

- "Climate Change: When will we Be certain? How Can we Explain why?" on April 16, 1992, The Franklin Institute hosted a one-day symposium on climate change and related issues in policy making and communications. Panel discussions between leading environmental scientists and print and broadcast journalist explored these controversial topics. (A brochure about the symposium is attached). 
- 8atellite Fieldtrip: Greenhouse Earth

In collaboration with the Black College satellite Network, the Franklin Institute hosted a one-hour educational program, broadcast live on May 11, 1992. Over 100,000 school children from school districts in Philadelphia, Dallas, Washington, D.C. and New York City participated in the "satellite fieldtrip." with the Greenhouse Earth exhibit as the centerpiece, the program explored the causes and effects of global warming, and the changes we can make in our everyday lives to help combat this environmental phenomenon. Highlights of the broadcast included live, call-in questions from students at each downlink site and two live experiments on carbon dioxide and hydrogen fuel cells.

\section{Evaluation}

The development of Greenhouse Earth was guided by front-end, formative, and summative evaluation procedures, employing both quantitative and qualicative measures. Evaluation includes interviews with visitors, prototypes of exhibit components, and summative survey forms for participating museums.

\section{- Front-end Evaluation}

Exhibit staff conducted front-end evaluation with training and advice from Minda Borun, Director of Education at the Institute and $a$ recognized leader in the field of museum research and evaluation.

During Fall 1990, Institute staff conducted front-end interviews with a sampling of 50 museum visitors in three age groups (under 21; 21$40 ; 40+)$. Interviews were designed to assess common levels of understanding about the basic scientific principles and the socioeconomic and environmental impact of climate change and global warming. The resulting data (see attachment) were used by exhibit staff in designing Greenhouse Earth devices, with particular attention to combatting widespread misconceptions and fulfilling public needs for practical information and advice.

A second round of front-end evaluation was conducted in the summer of 1991 to test the exhibit online, including titles, concepts and the balance of video, devices and graphics.

\section{- Formative Evaluation}

All of the devices in Greenhouse Earth were fabricated in prototype form and tested in the Summer and Fall of 1991 by Franklin Institute staff and members of the scientific advisory team. A random sample of museum visitors were also asked to experiment with prototypes, read explanatory text, and participate in interviews. This process determined each device's educational efficacy, ease of use, and visitor attraction.

Many modifications and improvements were made during this stage. For example, a component illustrating how gases can block heat was altered after being tested by visitors. Instead of using tanks 
filled with nitrogen and carbon dioxide for this component, exhibit staff used a ratan gel filter and a tank of water, which produced a more dramatic visual effect and was easier to see by visitors. The final design of the exhibit included final modifications to exhibit prototypes and subsequent retrials on the museum floor.

\section{- Summative Evaluation}

Two procedures will encompass the summative evaluation of Greenhouse Earth. First, during the exhibit's three-year tour, three sites will be selected to participate in summative studies of the cognitive

impact of the exhibit. At each site, 30 visitors in the three age groups describe above will be interviewed after visiting the exhibit, using the original questionnaire developed by The Franklin Institute. Responses will be compared to those of the front-end questionnaire to determine whether increases in knowledge have occurred as a result of exhibit exploration.

The second procedure will be directed by the Association of ScienceTechnology Centers, which requires all host museums to complete summative survey forms developed by The Franklin Institute. These forms will ask museums to summarize marketing and publicity programs, chronicle exhibit attendance, assess its affective and educational impact on visitors, and report on the museums' use of accompanying educational programs.

- Critical Review (in Boston)

A critical review of Greenhouse Earth was conducted by a group of 20 preeminent museum professionals, psychologists and representatives from the National science Foundation. Under the direction of Museum Evaluator Mark St. John, the group reviewed the exhibit for educational effectiveness as a case study for a long-term program to develop review criteria for exhibits.

\section{Conclusion}

During its stay in Philadelphia, Greenhouse Earth received widespread attention and praise from teachers, scientists, the general public. The exhibit was covered extensively by the local and national press, with reviews in print and broadcast media. (A press summary is attached). Informal interviews conducted by exhibit staff with visitors found that the exhibit was successful in responding to public interest through an approachable learning environment that promotes interaction. Most often heard by the Franklin Institute exhibit staff was that Greeniouse Earth was truly educational, as well as visually stunning. Many museums around the country have requested copies of several of the exhibit's devices for permanent installation at their institutions.

Greenhouse Earth is the first large-scale museum exhibit to address global climate change. It is traveling during a time when scientific 
evidence increasingly points to the reality and predicts the consequences of global warming. While the public has access to substantial media coverage of emerging data and theories about climate change, much of the information available is either too complex or insufficient. Through Greenhouse Earth, science museums are playing a significant role in the effort for public education. By providing direct experience with the tools, methods, concepts, and results of scientific research on global climate change, museums hosting Greenhouse Earth are providing visitors with a broad framework for understanding the difficult environmental, economic, and social implications of the changes that are taking place on our planet. 
DATE FILMED 12123192 
